\title{
Synaptic Circuit Abnormalities of Motor-Frontal Layer 2/3 Pyramidal Neurons in an RNA Interference Model of Methyl-CpG-Binding Protein 2 Deficiency
}

\author{
Lydia Wood, ${ }^{1}$ Noah W. Gray, ${ }^{2}$ Zhaolan Zhou, ${ }^{3}$ Michael E. Greenberg, ${ }^{4,5}$ and Gordon M. G. Shepherd ${ }^{1}$ \\ ${ }^{1}$ Department of Physiology, Feinberg School of Medicine, Northwestern University, Chicago, Illinois, 60611, ${ }^{2}$ Cold Spring Harbor Laboratory, Cold Spring \\ Harbor, New York 11724, ${ }^{3}$ Department of Genetics, University of Pennsylvania School of Medicine, Philadelphia, Pennsylvania 19104, ${ }^{4}$ Neurobiology \\ Program, Children's Hospital Boston, Boston, Massachusetts 02115, and 5Departments of Neurology and Neurobiology, Harvard Medical School, Boston, \\ Massachusetts 02115
}

Rett syndrome, an autism spectrum disorder with prominent motor and cognitive features, results from mutations in the gene for methyl-CpG-binding protein 2 (MeCP2). Here, to identify cortical circuit abnormalities that are specifically associated with MeCP2 deficiency, we used glutamate uncaging and laser scanning photostimulation to survey intracortical networks in mouse brain slices containing motor-frontal cortex. We used in utero transfection of short hairpin RNA constructs to knock down MeCP2 expression in a sparsely distributed subset of layer (L) 2/3 pyramidal neurons in wild-type mice, and compared input maps recorded from transfecteduntransfected pairs of neighboring neurons. The effect of MeCP2 deficiency on local excitatory input pathways was severe, with an average reduction in excitatory synaptic input from middle cortical layers (L3/5A) of $>30 \%$ compared with MeCP2-replete controls. $\mathrm{MeCP} 2$ deficiency primarily affected the strength, rather than the topography, of excitatory intracortical pathways. Inhibitory synaptic inputs and intrinsic eletrophysiological properties were unaffected in the MeCP2-knockdown neurons. These studies indicate that $\mathrm{MeCP} 2$ deficiency in individual postsynaptic cortical pyramidal neurons is sufficient to induce a pathological synaptic defect in excitatory intracortical circuits.

\section{Introduction}

Mouse models of monogenic neurological disorders provide powerful opportunities for identifying circuit-level abnormalities and for investigating how genetic mutations influence circuit development. Rett syndrome (RTT) (OMIM \#312750) is a severe monogenic neurodevelopmental disorder primarily afflicting girls, marked by early-onset motor-cognitive regression (Hagberg et al., 1983; Percy, 2002; Zoghbi, 2003). After the discovery that most RTT cases are caused by mutations in the X-linked gene encoding methyl-CpG-binding protein 2 (MeCP2) (Amir et al., 1999), several mouse models have been created (Chen et al., 2001; Guy et al., 2001; Shahbazian et al., 2002; Collins et al., 2004), launching intense investigation into how MeCP2 is tied to neural function and the RTT phenotype (Zoghbi, 2003; Moretti and Zoghbi, 2006; Chahrour and Zoghbi, 2007; Cohen and Greenberg, 2008; Cohen et al., 2008). Although knock-out

Received July 12, 2009; revised Aug. 26, 2009; accepted Sept. 2, 2009.

Support was provided by the Simons Foundation, the Rett Syndrome Research Foundation and International Rett Syndrome Foundation, and the National Institutes of Health (Grants NS061534 to L.W., NS058391 to Z.Z., NS048276 to M.E.G., and NS061963 to G.M.G.S.). We thank M. Bevan, A. Contractor, M. Hooks, G. Maccaferri, and M. Tresch for valuable input; C. Anderson, M. Eliava, B. Foxwell, B. Hitt, P. Osten, P. Penzes, T. Russell, G. Alheid, and W. Jiao for technical advice; and K. Svoboda for facilitating early stages of this work.

Correspondence should be addressed to Dr. Gordon Shepherd, Department of Physiology, Feinberg School of Medicine, Northwestern University, Morton 5-660, 303 East Chicago Avenue, Chicago, IL 60611. E-mail: g-shepherd@northwestern.edu.

D0I:10.1523/JNEUROSCI.3321-09.2009

Copyright $(\odot 2009$ Society for Neuroscience $\quad 0270-6474 / 09 / 2912440-09 \$ 15.00 / 0$ models provide valuable insight into pathological phenotypes associated with MeCP2 deficiency, they often cannot separate the primary effects from secondary, or compensatory, effects that manifest downstream of $\mathrm{MeCP} 2$ activity. The complexity of the $\mathrm{MeCP} 2$ pathway stems from its function as a transcriptional regulator, which binds methylated DNA (Lewis et al., 1992) and regulates genes related to neuronal and synaptic function, including brain-derived neurotrophic factor (BDNF) (Chen et al., 2003; Martinowich et al., 2003; Wang et al., 2006; Chahrour et al., 2008). The main function of MeCP2 within the CNS may be to guide experience-dependent maturation and regulation of neuronal circuits, rather than to promote neuronal survival or early circuit development (Kishi and Macklis, 2004; Cohen and Greenberg, 2008; Ramocki and Zoghbi, 2008).

Electrophysiological evidence points to a common defect of reduced excitatory synaptic input to cortical pyramidal neurons (Dani et al., 2005; Chao et al., 2007; Tropea et al., 2009). For L5 pyramidal neurons in somatosensory cortical slices from MeCP2null mice, reduced excitation was accompanied by increased inhibition (Dani et al., 2005); for L5 pyramidal neurons in sensorimotor slices from MeCP2-null mice, it was accompanied by reduced staining for the synaptic scaffolding protein PSD-95 and reduced dendritic spine density (Tropea et al., 2009); and, for monocultured MeCP2-null hippocampal neurons, reduced excitation correlated with reduced numbers of synapses (Chao et al., 2007). Together, these observations imply profound abnormalities in cortical excitatory networks due to MeCP2 deficiency. 
Motor features are prominent in RTT, including gait ataxia, apraxia, and loss of fine manual motor control (Hagberg et al., 1983; Bashina et al., 2002). Muscle responses evoked by cervical spinal cord stimulation are normal, but those evoked cortically show increased excitability, suggesting circuit abnormalities within motor cortex (Eyre et al., 1990). We recently mapped the excitatory synaptic network in mouse motor cortex (Weiler et al., 2008), providing a framework for investigating synaptic "circuitopathies" in mouse models of neurological disease affecting this brain area.

Here, we used RNA interference to downregulate MeCP2 expression in a subset of L2/3 pyramidal neurons, and laser scanning photostimulation (LSPS) to map local circuits, as a combined strategy to evaluate cell-specific effects of MeCP2 deficiency on cortical circuit organization.

\section{Materials and Methods}

In utero electroporation. All animal studies were performed in accordance with Northwestern University and NIH guidelines. In utero electroporation (IUEP) was performed following published protocols (Saito and Nakatsuji, 2001; Tabata and Nakajima, 2001; Gray et al., 2006). Pregnant female mice (C57BL/6, Charles River) at embryonic day E15 were anesthetized and the uterus surgically exposed. Glass pipettes were fabricated from capillary tubes (borosilicate, $5 \mu \mathrm{l}$; VWR International) using a vertical pipette puller (PC-10; Narashige), sharpened on a microgrinder (Narishige), and back-filled with a solution containing $0.6-1 \mu \mathrm{g} / \mu \mathrm{l}$ plasmid DNA in phosphate buffer and $1 \mathrm{mg} / \mathrm{ml}$ Fast Green (Sigma). Under stereomicroscopic visualization, electrodes were advanced into the right lateral ventricle of embryonic pups and $\sim 2 \mu$ l of plasmid solution was injected. The construct consisted of a bicistronic cassette encoding genes for a shRNA sequence targeted against MeCP2 driven by a U6 promoter, and GFP driven by a ubiquitin promoter (Fig. $1 \mathrm{~A}$ ) (for details, see Zhou et al., 2006). In control experiments, a plasmid with a scrambled sequence instead of the shRNA was used (Zhou et al., 2006). Electrodes were oriented to electroporate the right frontal cortex, and electroporation was accomplished using standard pulse parameters $(5$ pulses, $1 \mathrm{~Hz}$, $50 \mathrm{~ms}$ duration, $50 \mathrm{~V}$ ) for the electroporator (Nepa Gene). The abdominal wall was closed with absorbable sutures and the skin wound was closed with staples. Postoperative analgesic (flunixin, $2 \mathrm{mg} / \mathrm{kg}$ ) was administered every $12 \mathrm{~h}$ for $36 \mathrm{~h}$.

Immunohistochemistry. Brains were fixed by cardiac perfusion with fixative (4\% paraformaldehyde in PBS). Sections were cut by vibratome at a thickness of $50 \mu \mathrm{m}$ and incubated in blocking solution (3\% bovine albumin, $5 \%$ donkey serum, $0.02 \%$ Tween, $0.02 \%$ Triton X-100) overnight at $4^{\circ} \mathrm{C}$. Immunohistochemistry was performed using a polyclonal anti-MeCP2 antibody (Zhou et al., 2006) that recognizes MeCP2 regardless of phosphorylation state, and therefore labels total MeCP2 content within neurons. Slices were incubated with primary MeCP2-antibody $\left(0.5 \mu \mathrm{g} / \mathrm{ml}\right.$ anti-total MeCP2) at $4^{\circ} \mathrm{C}$ overnight, and then with Alexa 594-conjugated secondary antibody diluted 1:500 in blocking solution at $21^{\circ} \mathrm{C}$ for $2 \mathrm{~h}$ in the dark. Epifluorescence images were obtained with a cooled CCD camera (Retiga R-2000, QImaging).

Electrophysiology and LSPS. Brain slice preparation, electrophysiological recording, and LSPS mapping were performed as described (Weiler et al., 2008). Briefly, mice (age range: postnatal day 21-28) were killed and brains were blocked and mounted in chilled solution (in mm: 110 choline chloride, $25 \mathrm{NaHCO}_{3}, 25 \mathrm{D}$-glucose, 11.6 sodium ascorbate, $7 \mathrm{MgSO}_{4}, 3.1$ sodium pyruvate, $2.5 \mathrm{KCl}, 1.25 \mathrm{NaH}_{2} \mathrm{PO}_{4}$, and $0.5 \mathrm{CaCl}_{2}$ ), and cut by microtome (Microm) to obtain off-sagittal cortical slices, $0.3 \mathrm{~mm}$ in thickness. Slices were transferred to standard ACSF (in mm: $127 \mathrm{NaCl}, 25 \mathrm{NaHCO}_{3}, 25$ D-glucose, $2.5 \mathrm{KCl}, 1 \mathrm{MgCl}_{2}$, $2 \mathrm{CaCl}_{2}$, and $1.25 \mathrm{NaH}_{2} \mathrm{PO}_{4}$, aerated with $95 \% \mathrm{O}_{2}, 5 \% \mathrm{CO}_{2}$ ). After incubating for $30-45 \mathrm{~min}$ at $35^{\circ} \mathrm{C}$, slices were kept at $22^{\circ} \mathrm{C}$ for up to $5 \mathrm{~h}$ before recording.

For LSPS recording, slices were transferred to the recording chamber of an LSPS-outfitted microscope (Shepherd and Svoboda, 2005) and held in place by gold weights. The bath solution consisted of ACSF plus caged
A

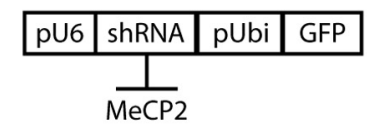

B
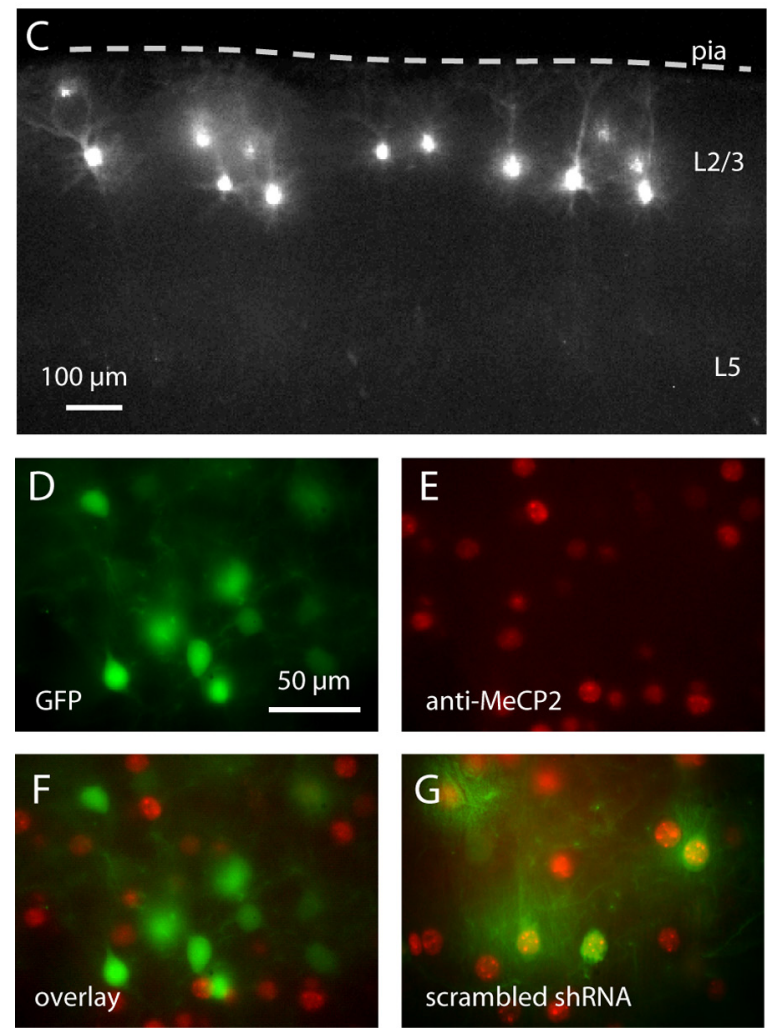

Figure 1. In utero electroporation method for knocking down MeCP2 in motor-frontal L2/3 pyramidal neurons. $\boldsymbol{A}$, Schematic of DNA plasmid depicting shRNA knockdown of $\mathrm{MeCP} 2$ and expression of GFP. $\boldsymbol{B}$, Timeline for surgery and LSPS experiments. C, GFP fluorescence image at low magnification of sparse transfection pattern in L2/3 at 3-4 weeks of age. Dotted line indicates pia. D, GFP expression in MeCP2 ${ }^{\mathrm{kd}}$ neurons in L2/3. $\boldsymbol{E}$, Anti-MeCP2 antibody staining, same field of view as in $\boldsymbol{D}$. $\boldsymbol{F}, 0$ verlay of GFP and antibody staining (images in $\boldsymbol{D}$ and $\boldsymbol{E}$ ) demonstrating efficient knockdown of MeCP2. G, Overlay of GFP and antibody staining for neurons transfected with a scrambled version of the anti-MeCP2 shRNA.

glutamate (0.2 mm; MNI-glutamate, Tocris Bioscience) (Canepari et al., 2001), $4 \mathrm{mM} \mathrm{Ca}^{2+}, 4 \mathrm{~mm} \mathrm{Mg}^{2+}$, and the NMDA receptor antagonist $R$-CPP ( $5 \mu \mathrm{M}$; Tocris Bioscience). The elevated divalent concentrations and NMDA antagonist dampened neuronal excitability (avoiding synaptically driven excitability), and prevented NMDA-mediated synaptic plasticity from occurring during mapping. These conditions have been found previously to limit the photoexcitability of presynaptic neurons to $\sim 1$ action potential per neuron per flash, within an area of cortex with radius of $\sim 70 \mu \mathrm{m}$ from the photostimulation beam; for the stimulus intensities used here, a cluster of $\sim 100$ presynaptic neurons is excited per photostimulus (Weiler et al., 2008). Furthermore, by blocking NMDA currents we were able to isolate AMPAergic synaptic responses. For intrinsic electrophysiological properties, recordings were made in current clamp, and CPP and MNI-glutamate were omitted. Neurons were targeted for patch recording with borosilicate pipettes (Warner). Pipettes were filled with either with (a) potassium methyl sulfate intracellular solution (in mм: $128 \mathrm{KCH}_{3} \mathrm{OSO}_{3}, 4 \mathrm{MgCl}_{2}, 10$ HEPES, 10 phosphocreatine, $4 \mathrm{Na}_{2} \mathrm{ATP}, 0.4 \mathrm{Na}_{2} \mathrm{GTP}, 3$ ascorbate, 1 EGTA; pH 7.25, 295 mOsm) containing Alexa-594 hydrazide (50 $\mu \mathrm{M}$; Invitrogen), or (b) cesium methanesulfonate intracellular solution, substituting equimolar $\mathrm{CsCH}_{3} \mathrm{O}_{3} \mathrm{~S}$ for the potassium salt, with $\mathrm{N}$-(2,6dimethylphenylcarbamoylmethyl)triethylammonium chloride (QX-314, 1 mM; Tocris Bioscience) added to block voltage-gated sodium and other channels. 
LSPS mapping conditions included $1.0 \mathrm{~ms}$ photostimuli, $20 \mathrm{~mW}$ stimulus power at the specimen plane, and 16-by-16 stimulus grids with $0.1 \mathrm{~mm}$ spacing. For each neuron, the stimulation grid was oriented to center it horizontally over the soma, and align its top edge with the pia. Synaptic inputs were recorded in voltage-clamp mode, and AMPAergic responses were isolated by recording in the presence of CPP at $-70 \mathrm{mV}$, the GABAergic reversal potential as measured empirically by GABA uncaging (Briggs and Callaway, 2005; Weiler et al., 2008). Series resistance was continually monitored during recordings, and recordings were rejected if it exceeded $30 \mathrm{M} \Omega$. Series resistance did not differ by cell type [for $\mathrm{K}^{+}$-based recordings, wild type (WT): $16 \pm 1 \mathrm{M} \Omega$; $\mathrm{MeCP} 2^{\mathrm{kd}}: 17 \pm 1 \mathrm{M} \Omega$; for $\mathrm{Cs}^{+}$-based recordings, WT: $19 \pm 1 \mathrm{M} \Omega$; MeCP2 ${ }^{\mathrm{kd}}: 17 \pm 1 \mathrm{M} \Omega$ ). Inhibitory GABAergic responses were recorded at $+15 \mathrm{mV}$ using $\mathrm{K}^{+}$-based intracellular solution (Shepherd et al., 2003; Dani et al., 2005) and $+5 \mathrm{mV}$ using $\mathrm{Cs}^{+}$-based intracellular solution, near the glutamatergic reversal potential as empirically determined by glutamate uncaging close to the soma. The difference in reversal potentials between the two solutions reflects the improved voltage control with intracellular cesium and QX-314. Maps were sampled across 2-3 trials. Additional details about the LSPS system used here have been published recently (Weiler et al., 2008). Data acquisition was controlled by Ephus software (http://openwiki.janelia.org).

Analysis of intrinsic properties. Current-clamp recordings of voltage transients evoked by small current steps were analyzed to estimate membrane time constant and input resistance $(n=6 \mathrm{WT}$ and 6 $\mathrm{MeCP} 2^{\mathrm{kd}}$ neurons). Responses to a family of current steps $(0.5 \mathrm{~s}$ duration) were analyzed to determine subthreshold voltage-current relationships, based on the average voltage over the last $100 \mathrm{~ms}$ of the steps. Rheobase was defined as the lowest-amplitude current step evoking at least one action potential. Spike frequency adaptation (SFA) was defined as the ratio of the third to fifth interspike interval, measured for the lowest-amplitude current step evoking at least six action potentials.

LSPS data analysis and interpretation. Data were analyzed using custom MATLAB (MathWorks) routines. Data were analyzed as described previously (Weiler et al., 2008; Yu et al., 2008). Briefly, LSPS traces were averaged over a $0-50 \mathrm{~ms}$ poststimulus time window to obtain the average excitatory current amplitude. Dendritic responses contaminated the synaptic traces for sites in the vicinity of the soma. These events were identified by latency analysis (Schubert et al., 2001) and such traces were excluded from further map analyses. The resulting values were mapped onto their position within the stimulation grid, generating a map of synaptic inputs. Several (2-3) input map trials were collected for each cell, and these were first analyzed to generate as many single-trial maps, and then these were averaged to obtain one average map of input amplitudes per neuron. Maps from multiple cells were then pooled and averaged to obtain group-average maps.

For a discussion of issues involved in the interpretation of LSPS data the reader is referred to previous studies (Weiler et al., 2008). LSPS maps provide information about the strengths of intracortical pathways, but not about quantal parameters such as unitary connection amplitudes. Also, because whole-cell recordings were made from neuronal somata, not dendrites, our data give a somatocentric view of circuits. Our results therefore do not preclude the possibility of additional circuit changes affecting synapses located in more distal portions of dendritic arbors.

Statistics. Except where noted, intergroup comparisons were made using Student's paired $t$ test, with significance defined as $p<0.05$. Unless otherwise stated, group statistics are presented as mean \pm SEM.
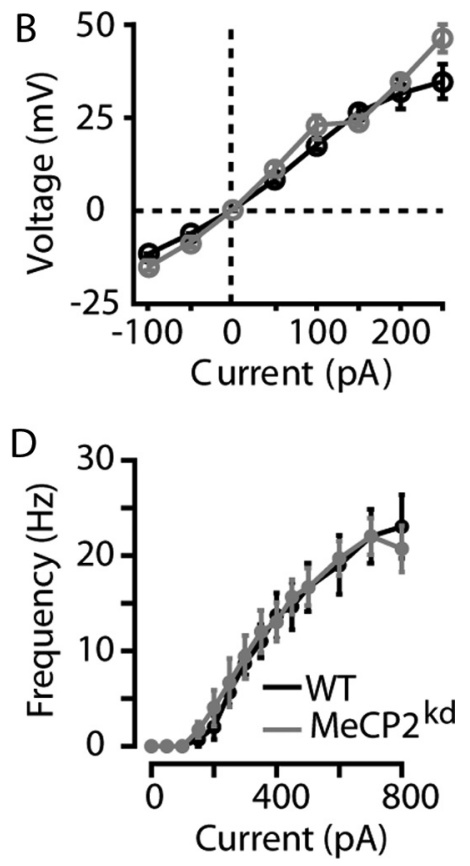

Figure 2. $\mathrm{MeCP} 2^{\mathrm{kd}}$ neurons have WT-like electrophysiological properties. $\boldsymbol{A}$, Traces recorded in current clamp of voltage reponses to both negative and positive subthreshold current steps. Bars, $5 \mathrm{mV}, 100 \mathrm{~ms}$. $\boldsymbol{B}$, Voltage-current relationships for WT (black) and $\mathrm{MeCP} 2^{\mathrm{kd}}$ (gray) neurons. C, Example traces showing repetitive firing characteristics. Bars, $25 \mathrm{mV}, 100 \mathrm{~ms}$. D, Frequencycurrent relationships for WT and $\mathrm{MeCP}{ }^{\text {kd }}$ neurons.

\section{Results}

In this study, we focused on L2/3 pyramidal neurons, both because (1) in motor cortex, L2/3 is a key node in the local excitatory network, receiving inputs from $\mathrm{L} 3 / 5 \mathrm{~A}$ and providing the major source of excitatory input to L5 (Weiler et al., 2008), a major cortical output layer (Jones, 1984); and (2) we were interested in testing whether MeCP2 deficiency in these neurons induced synaptic abnormalities as previously observed for L5 neurons (Dani et al., 2005). We used LSPS (Callaway and Katz, 1993; Katz and Dalva, 1994) to map excitatory synaptic inputs in MeCP2-deficient neurons. To overcome difficulties in separating primary, or cell-specific, effects of MeCP2 deficiency from downstream signaling abnormalities or homeostatic mechanisms, we used a cell-specific model system of MeCP2 deficiency. An advantage of this cell-specific knockdown approach is the ability to distinguish pre- versus postsynaptic effects of MeCP2 deficiency (in contrast to mutant models in which all neurons lack MeCP2). We generated MeCP2-knockdown neurons $\left(\mathrm{MeCP} 2^{\mathrm{kd}}\right)$ in vivo, using RNA interference to downregulate $\mathrm{MeCP} 2$ expression in a sparsely distributed subset of L2/3 pyramidal neurons.

\section{RNA interference-mediated knockdown of MeCP2 in motor-frontal L2/3 pyramidal neurons}

Previous studies have identified abnormalities in brains of Rett patients and mutant-mouse models of MeCP2 deficiency (Blue et al., 1999; Dani et al., 2005; Fukuda et al., 2005; Asaka et al., 2006; Chao et al., 2007; Belichenko et al., 2009). However, abnormalities revealed by studies of genetic mutations, even when expression is regionally restricted (Chen et al., 2001; Guy et al., 2001; Alvarez-Saavedra et al., 2007) can potentially reflect either cellspecific effects of MeCP2 depletion or compensatory homeostatic mechanisms engaged more globally to counter altered gene expression. To address whether MeCP2 deficiency affects excitatory synaptic input in a cell-specific manner, we used a knockdown strategy in which MeCP2 deficiency was restricted to a 

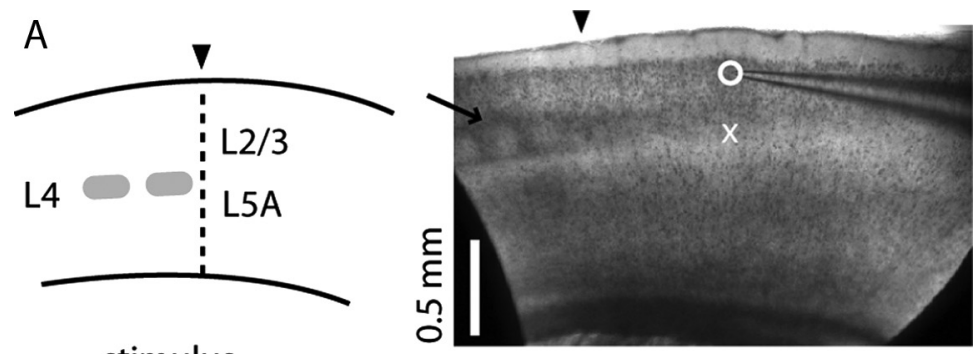

stimulus

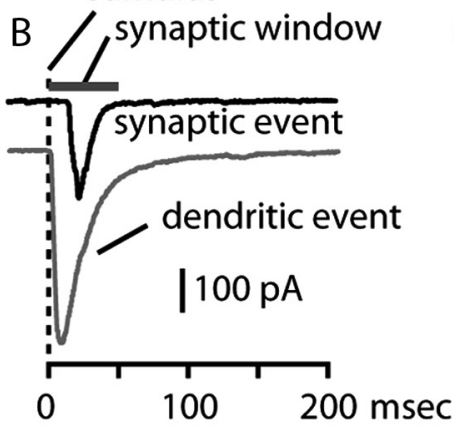

C

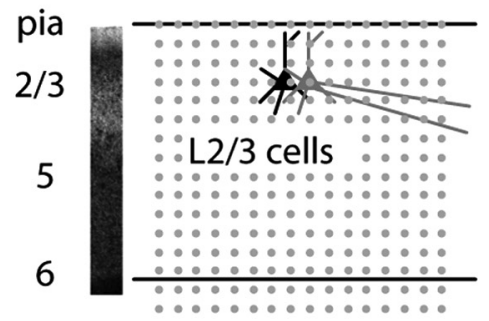

mapping grid

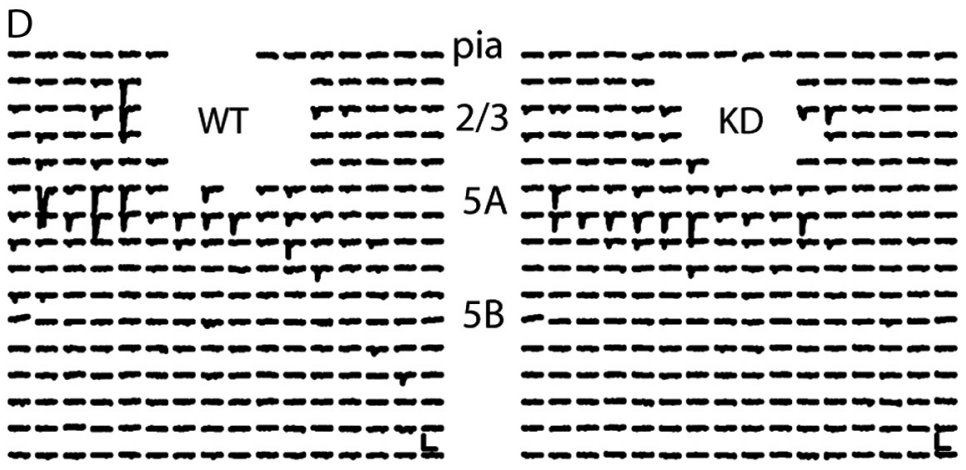

Figure 3. LSPS method for mapping excitatory inputs to neighboring transfected and untransfected pairs of neurons. $A$, Schematic (left) and bright field image (right) of the parasagittal slices used in this study. Anterior is to the right. Arrow: L4 barrels in S1. Arrowheads, border between primary somatosensory (S1) and primary motor (M1) cortex. Circle, soma of recorded neuron, and stimulus location for gray trace shown in $\boldsymbol{B}$; cross, stimulus location for black trace in $\boldsymbol{B}$. $\boldsymbol{B}$, Examples of dendritic and synaptic responses evoked by glutamate uncaging photostimulation, at the sites indicated in $\boldsymbol{A}$. Traces were recorded at the same holding potential (displayed with offset for clarity). C, Recording arrangement. Left, Bright field image, showing cortical layers. Right, Array of dots represents 16 -by-16 site stimulus grid with $0.1 \mathrm{~mm}$ spacing. Gray and black neurons represent $\mathrm{MeCP}{ }^{\mathrm{kd}}$ and WT neurons, respectively. Top and bottom lines represent pia and white matter, respectively. $\boldsymbol{D}$, Examples of arrays of traces recorded from WT and MeCP2 ${ }^{\mathrm{kd}}$ neurons, using the stimulus grid shown in C. Scale bar, $100 \mathrm{~ms}, 50 \mathrm{pA}$.

small percentage of individual postsynaptic L2/3 pyramidal neurons distributed within a cortical network consisting largely of WT neurons. An aspect of this approach that is also potentially relevant for the pathophysiology of Rett syndrome is that this transfection pattern resembles the mosaic distribution of MeCP2-deficient neurons in the cortex of Rett patients (mostly girls) due to X-chromosome inactivation.

IUEP was performed on embryonic WT mice to transfect individual L2/3 neural progenitor cells with a plasmid encoding GFP and shRNA targeted against MeCP2 (Zhou et al., 2006) (Fig. $1 A-C)$. Efficient knockdown of MeCP2 expression in GFPpositive neurons was confirmed by immunohistochemistry (Fig. $1 D-F)$, as was a lack of knockdown with a scrambled version of the plasmid (Fig. 1G). Although these results do not preclude the possibility of low-level residual MeCP2 expression, together with the mapping studies presented later they do indicate that the knockdown was sufficiently efficient to reduce MeCP2 expression to undetectable levels and to induce circuit abnormalities. GFP expression in transfected neurons remained high at 3-4 weeks, when recordings were made. Cortical thickness was not significantly different compared with unoperated control mice (controls: $1378 \pm 21, n=11$ animals; MeCP2 $2^{\mathrm{kd}}: 1336 \pm 13 \mu \mathrm{m}, n=9$ animals). By timing IUEP with respect to the inside-out process of cortical development the transfection was restricted to neurons in L2/3 (Fig. 1C). Moreover, only pyramidal neurons were transfected, not inhibitory interneurons (Noctor et al., 2001, 2002; Borrell et al., 2005).

The electroporation protocol used here resulted in fairly sparse labeling of L2/3 neurons. We quantified the percentage of labeled L2/3 neurons by counting the number of GFP-positive neurons per high-power field in the transfected region of motor-frontal cortex. On average, $15.5 \pm 1.5 \%$ of $\mathrm{L} 2 / 3$ neurons expressed GFP ( $n=4$ animals, 422 cells total). No L5 neurons expressed GFP.

MeCP $2^{\mathrm{kd}}$ and WT neurons have similar electrophysiological properties We recorded from $\mathrm{L} 2 / 3$ neurons in motor-frontal cortex and assessed their intrinsic properties. $\mathrm{MeCP} 2^{\mathrm{kd}}$ and $\mathrm{WT}$ neurons did not differ significantly in resting membrane potential (WT: $-74 \pm 2$ $\mathrm{mV}$; $\mathrm{MeCP}^{\mathrm{kd}}:-72 \pm 4 \mathrm{mV}$ ), input resistance (WT: $134 \pm 10 \mathrm{M} \Omega$; $\mathrm{MeCP}^{\mathrm{kd}}$ : $180 \pm 26 \mathrm{M} \Omega$ ), or membrane time constant (WT: $39.2 \pm 8.1 \mathrm{~ms} ; \mathrm{MeCP}^{\mathrm{kd}}$ : $33.7 \pm 8.8 \mathrm{~ms}$ ). We further characterized the electrophysiological properties of $\mathrm{MeCP} 2^{\mathrm{kd}}$ and WT pairs of neurons by recording responses in current-clamp mode to a family of current steps. Voltage-current relationships for WT and $\mathrm{MeCP} 2^{\mathrm{kd}}$ neurons did not differ significantly $(p=$ 0.50, 2-way ANOVA) (Fig. $2 A, B$ ). We also compared the firing properties of WT and $\mathrm{MeCP} 2^{\mathrm{kd}}$ neurons (Fig. 2C). Rheobase was indistinguishable (WT: $225 \pm 21 \mathrm{pA}$; MeCP2 ${ }^{\mathrm{kd}}: 217 \pm 31$ $\mathrm{pA}$ ), as was the average half-width of action potentials (WT: $\left.1.2 \pm 0.1 \mathrm{~ms} ; \mathrm{MeCP}^{\mathrm{kd}}: 1.3 \pm 0.1 \mathrm{pA}\right)$. Furthermore, neither f-I relationships ( $p=0.47,2$-way ANOVA) (Fig. $2 D)$ nor SFA differed between groups (WT: $0.86 \pm 0.05 ; \mathrm{KD}: 0.88 \pm 0.01$ ). From these tests we concluded that the intrinsic neurophysiological properties of $\mathrm{MeCP}^{\mathrm{kd}}$ neurons largely resembled those of untransfected neurons.

\section{Excitatory synaptic input to $\mathrm{MeCP} 2^{\mathrm{kd}}$ neurons is} specifically reduced

To map the local sources of excitatory input to these neurons, we used glutamate uncaging and laser scanning photostimulation (LSPS). The basic principles of LSPS circuit mapping are as follows (for review, see Katz and Dalva, 1994; Shepherd, 2006). Caged glutamate is added to the solution bathing a cortical slice, and recording is established on a neuron whose inputs are to be mapped. Photo-release of glutamate by a flash of focused UV light directed to a particular location in the slice activates gluta- 
mate receptors on somatodendritic membranes and depolarizes neurons (axons of passage are not activated). Conditions are optimized and calibrated such that individual flashes activate only small numbers of neurons clustered around the center of the beam to fire action potentials. Synaptic inputs from the photostimulated (presynaptic) neurons to the recorded (postsynaptic) neuron are recorded as events in the electrophysiological trace. These events represent the aggregate connectivity from the $\sim 100$ or so stimulated neurons onto the recorded neuron. By sequentially sampling hundreds of stimulation sites in a patterned photostimulation grid, a map of the local sources of synaptic inputs converging onto one neuron is generated. The resolution of stimulation (typically $\sim 50-100 \mu \mathrm{m}$ ) is suitable for detailed mapping of inputs on the mesoscopic scale of the local circuit topography (typically $0.5-1.0 \mathrm{~mm}$ ). For further details, see Weiler et al. (2008).

We used LSPS stimulation parameters previously characterized for this slice preparation (Weiler et al., 2008). AMPAergic responses were isolated by (1) recording at the GABAergic reversal potential; (2) blocking NMDA receptors; and (3) rejecting traces contaminated by dendritic responses, arising from stimulation of glutamate receptors on the postsynaptic neuron (Katz and Dalva, 1994; Pettit et al., 1999; Schubert et al., 2001) (Fig. 3A,B). Dendritic responses only occurred in the vicinity of the somatodendritic region of the neuron and were readily identified by their characteristic short latencies, and were excluded from synaptic input maps (Weiler et al., 2008).

We recorded from L2/3 neurons in motor-frontal cortex, identifying this cortical area by its location anterior to barrel cortex and agranular cytoarchitectonic features (Weiler et al., 2008; Yu et al., 2008), readily apparent in these off-sagittal slices (Fig. 3A). We targeted nearby $(<100 \mu \mathrm{m}) \mathrm{MeCP} 2^{\mathrm{kd}}$ and WT neurons, a paradigm enabling direct comparison between neighboring neurons (Fig. 3C) embedded within the same area of WT cortex, differing in their MeCP2 expression. Neurons were mapped sequentially, as this has been shown to yield results statistically identical to simultaneously mapped pairs (Shepherd and Svoboda, 2005) and was a more efficient approach in these experiments. Traces that did not contain direct responses (Fig. $3 B$ ) were analyzed to obtain excitatory maps for the neurons in each transfected/untransfected pair.

Excitatory inputs arose from locations directly below the recorded neurons, at approximately the border between L3 and $\mathrm{L} 5 \mathrm{~A}$, and from lateral locations in L2/3. For display, these trace arrays were analyzed to generate maps representing the average postsynaptic current over a $50 \mathrm{~ms}$ poststimulus time window (Fig. 4). Synaptic input maps recorded in $\mathrm{K}^{+}$- and $\mathrm{Cs}^{+}$-based intracellular solution showed similar amplitude and topographic organization (Fig. 4).

To compare excitatory maps of untransfected versus transfected neurons recorded with $\mathrm{K}^{+}$-based intracellular solution ( $n=13$ pairs), we pooled maps and calculated the average map for each group (Fig. 5A). A locus of input was found below the region containing the soma (black pixels), representing ascending $\mathrm{L} 3 / 5 \mathrm{~A} \rightarrow 2 / 3$ excitatory connections. Computing a vertical laminar profile (Fig. $5 B$ ) showed that the main locus of reduced input occurred $0.4-0.6 \mathrm{~mm}$ below the pia, at the L3/5A border. Pixels averaged over this region of interest (ROI) showed a significant reduction in $\mathrm{MeCP} 2^{\mathrm{kd}}$ neurons. These data revealed significantly weaker excitatory inputs for the $\mathrm{MeCP} 2^{\mathrm{kd}}$ neurons (reduced by $33 \%$ ) to neurons in L2/3 (WT: $11.3 \pm 1.7 \mathrm{pA}$; $\mathrm{MeCP} 2{ }^{\mathrm{kd}}: 7.6 \pm 1.7 \mathrm{pA}$ ) (Fig. $5 C$ ).
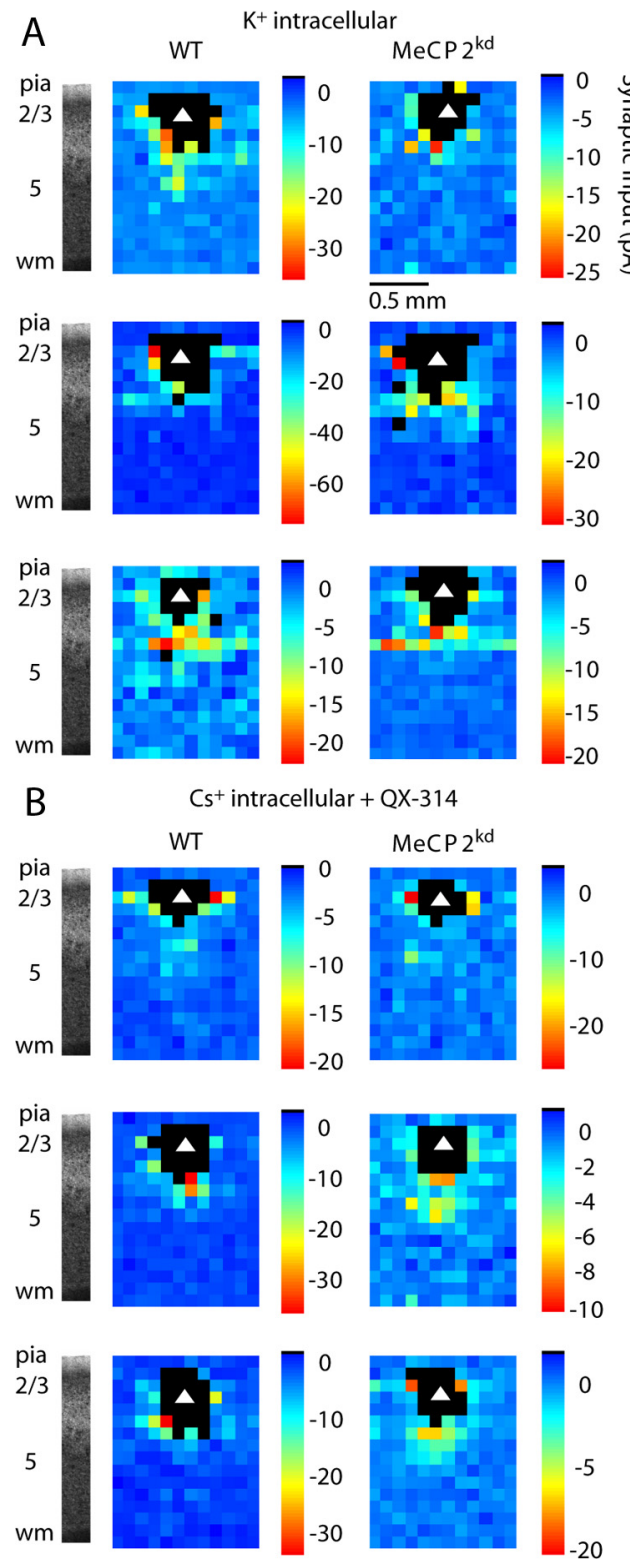

Figure 4. Example maps from neighboring pairs of $\mathrm{MeCP} 2^{\mathrm{kd}}$ and WT pyramidal neurons. $\boldsymbol{A}$, Maps obtained from neighboring pyramidal neurons, made with $\mathrm{K}^{+}$-based intracellular solution. White triangle indicates position of recorded soma relative to the map. Pixels containing direct responses are blacked out. Slice image (left) shows location of map relative to laminar slice landmarks, with the top of the stimulation grid aligned to pia. Maps have been zoomed slightly for display, showing topographic features in the central region of interest. $\boldsymbol{B}$, Recordings made with $\mathrm{Cs}^{+}$-based intracellular solution containing $1 \mathrm{~mm}$ QX-314.

In contrast to the ascending $\mathrm{L} 3 / 5 \mathrm{~A}$ inputs, horizontal inputs to $\mathrm{L} 2 / 3$ neurons, from locations in L2/3 lateral to the recorded neurons, were not significantly different between WT and $\mathrm{MeCP} 2^{\mathrm{kd}}$ (WT: $8.6 \pm 2.9$ pA; MeCP2 ${ }^{\mathrm{kd}}: 6.6 \pm 1.3$ pA) (Fig. $5 D$ ). Therefore, the reduced excitatory synaptic input was apparently specific to the $\mathrm{L} 3 / 5 \mathrm{~A} \rightarrow 2 / 3$ cortical pathway.

To verify these findings, we performed mapping experiments using a $\mathrm{Cs}^{+}$-based intracellular solution containing $1 \mathrm{~mm} \mathrm{QX-}$ 314 (Fig. $4 B$ ) that provided better voltage control for excitatory maps (presented in this section) and inhibitory maps (presented in the next section). Group analysis of this second set of experiments again showed a locus of input to WT neurons just below the region containing the cell body, confirming the differences 

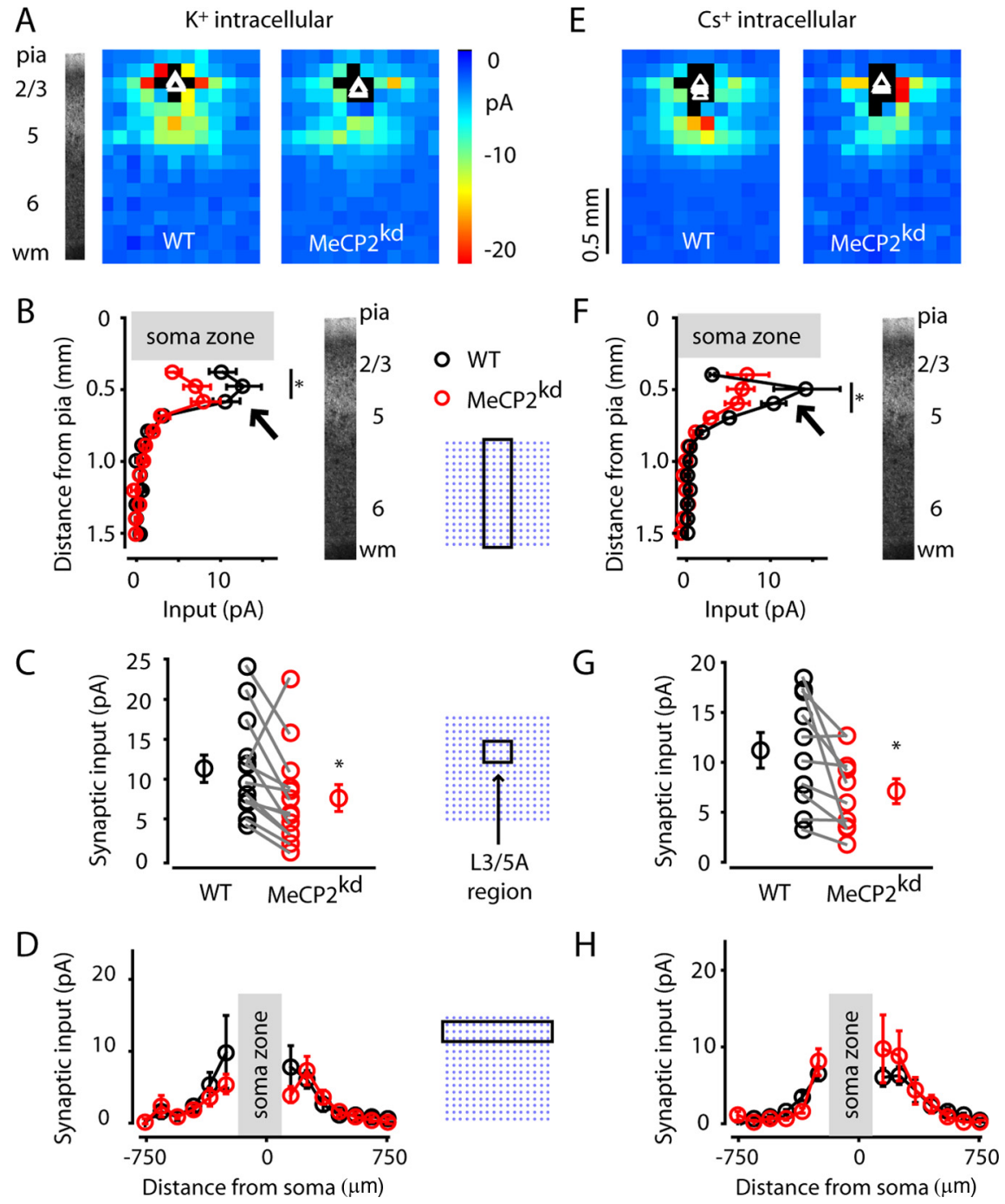

Figure 5. Local sources of excitatory synaptic input to transfected/untransfected pairs of $L 2 / 3$ pyramidal neurons. $A$, Average maps taken from $n=13$ neighboring pairs of WT and $\mathrm{MeCP} 2{ }^{\mathrm{kd}} \mathrm{L} 2 / 3$ pyramidal neurons. Data shown in $\boldsymbol{A}-\boldsymbol{D}$ were recorded with $\mathrm{K}^{+}$-based intracellular solution. Slice image (left) shows location of map relative to the laminar pattern of motor-frontal cortex, and applies to maps in $\boldsymbol{A}$ and $\boldsymbol{E}$. Color scale bar (right) applies to maps in $\boldsymbol{A}$ and $\boldsymbol{E}$. Maps have been zoomed slightly for display, showing topographic features in the central region of interest. $\boldsymbol{B}$, Left, Vertical profile showing laminar locations of synaptic input to $L 2 / 3$, from neurons in $\boldsymbol{A}$. The region surrounding the soma is blanked out due to contaminating direct responses. Right, Stimulation grid with region of interest (black rectangle) applies to vertical profiles in $\boldsymbol{B}$ and $\boldsymbol{F}$. Asterisk shows significantly different row averages. C, Left, Average inputs from a $300 \times 400 \mu \mathrm{m}$ region, $400-600 \mu \mathrm{m}$ from the pia, containing the L3/5A border (shown right; black rectangle). Lines connect pairs of neighboring WT and $\mathrm{MeCP} 2^{\mathrm{kd}}$ neurons. Asterisk indicates significantly reduced synaptic input from the $\mathrm{L} 3 / 5 \mathrm{~A}$ region. Stimulation grid with $\mathrm{L} 3 / 5 \mathrm{~A}$ region outlined applies to region averages in $\mathbf{C}$ and $\mathbf{G}$. D, Left, Horizontal profile showing L2/3 input. Right, Stimulation grid with region of interest (black rectangle) applies to horizontal profiles in $\boldsymbol{D}$ and $\boldsymbol{H}$. $\boldsymbol{E}$, Average maps taken from $n=10$ pairs of $\mathrm{MeCP}{ }^{\mathrm{kd}}$ and $\mathrm{L} 2 / 3$ pyramidal neurons. Data shown in $\boldsymbol{E}-\boldsymbol{H}$ were recorded in $\mathrm{CS}^{+}$-based intracellular solution. $\boldsymbol{F}$, Vertical profile showing laminar locations of synaptic input to $L 2 / 3$, from neurons in $\boldsymbol{E}$. Asterisk shows significantly different row averages. $\boldsymbol{G}$, Average inputs showing significantly reduced synaptic input from the region shown in C (right). H, Horizontal profile showing L2/3 input.

observed with $\mathrm{K}^{+}$-based internal solution (Fig. $5 E$ ). Both the vertical profile and the region average showed significantly reduced input from the $\mathrm{L} 3 / 5 \mathrm{~A}$ region (WT: $11.1 \pm 1.8 \mathrm{pA}$; MeCP2 ${ }^{\mathrm{kd}}: 7.1 \pm 1.2 \mathrm{pA}, 36 \%$ reduction) (Fig. $\left.5 F, G\right)$. As found with $\mathrm{K}^{+}$-based intracellular solution, the L2/3 input was not significantly different between the two groups (WT: $6.2 \pm 0.8 \mathrm{pA}$; $\mathrm{MeCP} 2^{\mathrm{kd}}: 8.6 \pm 2.2 \mathrm{pA}$ ) (Fig. $5 H$ ), confirming that the synaptic excitatory phenotype induced by $\mathrm{MeCP} 2$ deficiency was pathway specific. Because the $\mathrm{L} 2 / 3$ region contained dendritic responses, this region contained fewer data points than the L3/5A region, potentially reducing the power of statistical tests to detect a difference.
However, even when the excitatory maps from both $\mathrm{K}^{+}$- and $\mathrm{Cs}^{+}$-based intracellular recordings were pooled, effectively doubling the number of samples for each cell type, the L2/3 input still was not significantly altered in the $\mathrm{MeCP} 2{ }^{\mathrm{kd}}$ neurons (WT: $7.5 \pm 1.6 \mathrm{pA}$; $\left.\mathrm{MeCP} 2^{\mathrm{kd}}: 7.4 \pm 1.2 \mathrm{pA}\right)$.

To rule out the potential effects of electroporation, shRNA, and exogenous GFP expression, in separate experiments we transfected animals with a plasmid containing a scrambled version of the shRNA sequence (Zhou et al., 2006). Excitatory inputs were not significantly different between scrambled versus untransfected neighboring neurons ( $n=11$ pairs) (Fig. 6). Although shRNAs can potentially induce an interferon response and synaptic abnormalities including reduced EPSP amplitude (Sledz and Williams, 2004; Alvarez et al., 2006), such effects are sequence specific, and the sequence used here was previously shown not to induce dendritic and spine morphological abnormalities when cotransfected with replacement MeCP2 (Zhou et al., 2006). We therefore interpret the synaptic circuit changes observed here to result specifically from the knockdown of MeCP2.

\section{Inhibitory responses are unchanged in MeCP $2^{\mathrm{kd}}$ pyramidal neurons}

The preceding experiments were all aimed at measuring AMPAergic responses, with the contribution of inhibitory responses minimized by recording at the GABAergic reversal potential. To measure inhibitory inputs, for a subset of the neurons we obtained inhibitory input maps by recording at the reversal potential for glutamatergic responses. In separate experiments, we determined that bath application of the selective $\mathrm{GABA}_{\mathrm{A}}$ antagonist SR95531 (gabazine, $10 \mu \mathrm{M}$, Tocris Bioscience) completely blocked these outward currents ( $n=3 \mathrm{WT}$ neurons, Fig. $7 A$ ), confirming in this system that these were indeed fast GABAergic events (Brill and Huguenard, 2008). For recordings with $\mathrm{K}^{+}$-based intracellular solution, we again excluded perisomatic sites where strong dendritic excitatory conductances accompanied inhibitory inputs. However, for $\mathrm{Cs}^{+}$-based recordings we included all stimulation sites because dendritic excitatory events were better voltage-clamped. Inhibitory maps were similar in both topography and strength between $\mathrm{MeCP} 2^{\mathrm{kd}}$ neurons and their WT neighbors $\left(\mathrm{K}^{+}\right.$-based, $n=13$ pairs: WT: $46.0 \pm 11.9 \mathrm{pA} ; \mathrm{MeCP}^{\mathrm{kd}}: 47.8 \pm 9.5 \mathrm{pA}$; $\mathrm{Cs}^{+}$-based: WT: $\left.175.1 \pm 36.4 \mathrm{pA} ; \mathrm{MeCP}^{\mathrm{kd}}: 173.4 \pm 35.1 \mathrm{pA}\right)($ Fig. $7 B-D)$. These results demonstrate that the reduction in excitatory pathway strength found for the MeCP2 ${ }^{\mathrm{kd}}$ neurons was not accompanied by changes in local inhibitory pathways. 


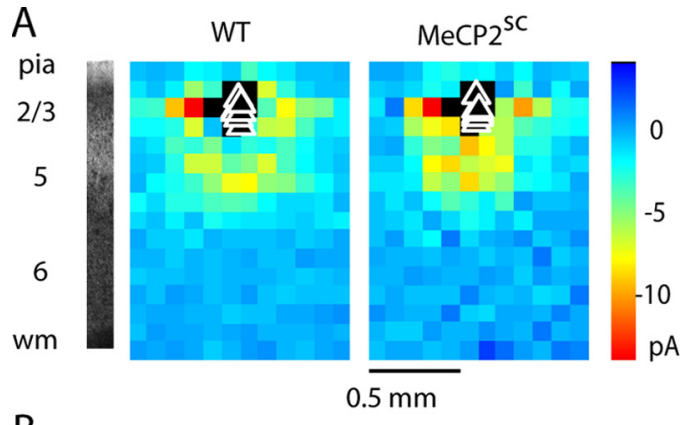

B
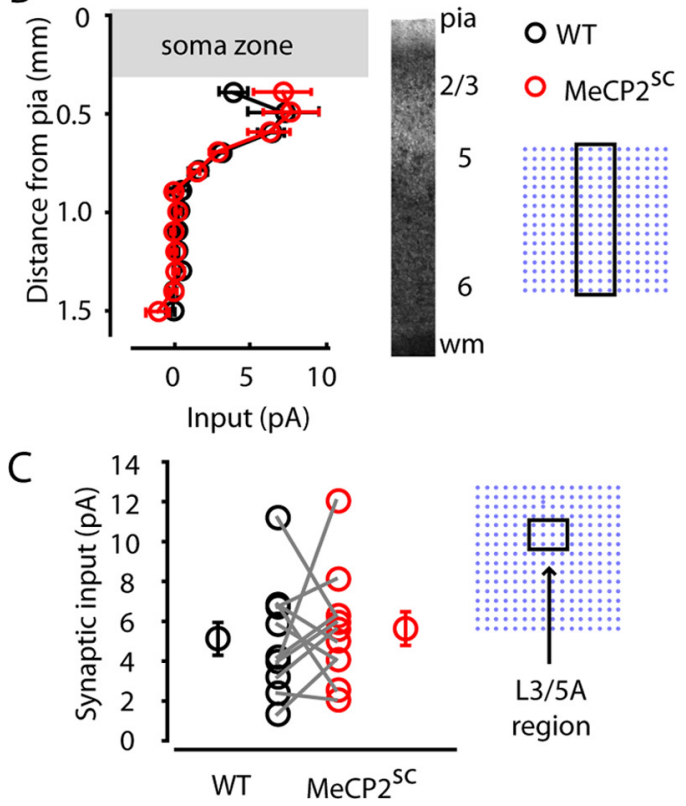

Figure 6. Scrambled control shows no change in excitatory input to $L 2 / 3$ neurons. $A$, Average maps taken from $n=11$ pairs of WT and MeCP2 ${ }^{\mathrm{SC}} \mathrm{L} 2 / 3$ pyramidal neurons recorded with $\mathrm{K}^{+}$-based intracellular solution. Slice image (left) shows location of map relative to the laminar pattern of motor-frontal cortex. Maps have been zoomed slightly for display, showing topographic features in the central region of interest. $\boldsymbol{B}$, Left, Vertical profile showing laminar locations of synaptic input to $L 2 / 3$. The region surrounding the soma is blanked out due to contaminating direct responses. Right, Stimulation grid with columnar region of interest. C, Left, Average inputs from a $300 \times 400 \mu \mathrm{m}$ region containing the L3/5A border (shown right; black rectangle). Lines connect pairs of neighboring WT and $\mathrm{MeCP}^{\mathrm{SC}}$ neurons.

\section{Discussion}

A combination of IUEP-mediated transfection to knockdown MeCP2 expression in L2/3 pyramidal neurons and LSPS microscopy to map synaptic inputs was used to identify cortical circuit abnormalities in motor-frontal cortex associated with MeCP2 deficiency. Our main finding was a reduction in the ascending excitatory synaptic pathway from L3/5A to L2/3. Despite changes in synaptic pathway strength, circuit topography was not affected, with $\mathrm{L} 2 / 3$ receiving ascending input from $\mathrm{L} 3 / 5 \mathrm{~A}$ and lateral input from L2/3.

In contrast to MeCP2-null animals, in which presynaptic and postsynaptic effects are difficult to distinguish (because the mutation is expressed in all neurons), with $\mathrm{MeCP} 2^{\mathrm{kd}}$ neurons the changes can be localized to the postsynaptic neuron. Using this strategy, we determined that postsynaptic knockdown of MeCP2 was sufficient to induce a reduction in excitatory synaptic input resembling that observed previously in other synaptic circuits in MeCP2-null animals (Dani et al., 2005; Chao et al., 2007). We note that with our approach we largely assayed $\mathrm{WT} \rightarrow \mathrm{MeCP} 2^{\mathrm{kd}}$ inputs (transfection targeted only $\sim 15 \%$ of L2/3 neurons); it would be of interest to evaluate $\mathrm{MeCP} 2^{\mathrm{kd}} \rightarrow \mathrm{WT}$ outputs as well, particularly as such experiments would in principle distinguish whether the cell-specific effects we observed are specifically postsynaptic, or both pre- and postsynaptic.

Region- and cell-specific manipulation of MeCP2 has been a key tool for unraveling the neural effects of MeCP2 deficiency. For example, loss of MeCP2 in forebrain recapitulates features of RTT (Chen et al., 2001; Guy et al., 2001; Gemelli et al., 2006). Here, we restricted MeCP2 deficiency to a subset of L2/3 pyramidal neurons in motor-frontal cortex. The MeCP2 $2^{\mathrm{kd}}$ approach showed that MeCP2-deficient neurons embedded in an otherwise normal network displayed an excitatory circuit phenotype similar to that found by others in MeCP2-null neurons. One implication of this is that circuit defects observed at the cortical level obey intrinsic wiring rules, and do not necessarily reflect compounded defects accruing from altered subcortical inputs. Interestingly, the excitatory phenotype was observed in L3/ $5 \mathrm{~A} \rightarrow 2 / 3$ but not $\mathrm{L} 2 / 3 \rightarrow 2 / 3$ pathways, suggesting that some intracortical synaptic pathways may be relatively spared despite postsynaptic MeCP2 deficiency.

We did not detect an inhibitory phenotype for $\mathrm{L} 2 / 3$ pyramidal neurons in motor-frontal cortex in either $\mathrm{K}^{+}$- or $\mathrm{Cs}^{+}$-based intracellular recordings, consistent with previous observations at the level of miniature inhibitory postsynaptic events, both for L5 pyramidal neurons in acute slices of S1 cortex in MeCP2-null mice (Dani et al., 2005) and for cultured hippocampal pyramidal neurons (Nelson et al., 2006). However, our findings do not rule out abnormalities in excitatory/inhibitory balance due to increased driving of interneurons or other mechanisms (Dani et al., 2005). The knockdown approach described here could be adapted to examine the local circuit organization of inhibitory neurons, using methods for selectively targeting interneurons (Borrell et al., 2005).

Although the strength of local excitatory pathways was markedly reduced by MeCP2 deficiency, the overall form of these pathways was intact; i.e., the changes were in circuit scaling, not circuit topography. A scale-altering, form-preserving type of circuitopathy would be consistent with (1) the remarkable reversal of the severe neurological impairments of adult MeCP2-deficient mice after restoring MeCP2 expression (Guy et al., 2007); (2) the idea that neocortical circuits can be functionally tuned and "rewired" at the microscopic level of nearby spines and boutons, within the framework of potential connectivity established by axonal and dendritic arbors (Trachtenberg et al., 2002; Chklovskii et al., 2004; Shepherd et al., 2005); and (3) the proposed role of MeCP2 in experience-dependent maintenance rather than developmental specification of neuronal circuits (Kishi and Macklis, 2004; Cohen and Greenberg, 2008; Ramocki and Zoghbi, 2008). The relative preservation of cortical circuit topography may have positive implications for RTT therapeutic possibilities.

\section{References}

Alvarez VA, Ridenour DA, Sabatini BL (2006) Retraction of synapses and dendritic spines induced by off-target effects of RNA interference. J Neurosci 26:7820-7825.

Alvarez-Saavedra M, Sáez MA, Kang D, Zoghbi HY, Young JI (2007) Cellspecific expression of wild-type MeCP2 in mouse models of Rett syndrome yields insight about pathogenesis. Hum Mol Genet 16:2315-2325.

Amir RE, Van den Veyver IB, Wan M, Tran CQ, Francke U, Zoghbi HY (1999) Rett syndrome is caused by mutations in X-linked MECP2, encoding methyl-CpG-binding protein 2. Nat Genet 23:185-188.

Asaka Y, Jugloff DG, Zhang L, Eubanks JH, Fitzsimonds RM (2006) Hippocampal synaptic plasticity is impaired in the Mecp2-null mouse model of Rett syndrome. Neurobiol Dis 21:217-227.

Bashina VM, Simashkova NV, Grachev VV, Gorbachevskaya NL (2002) 
A

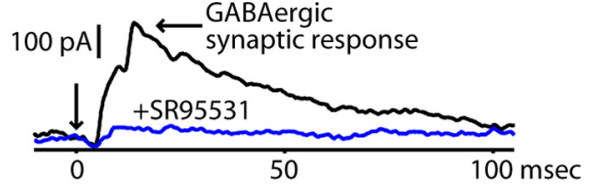

B

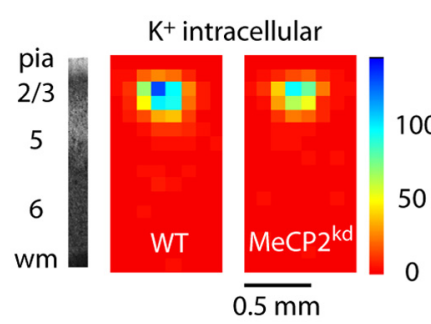

C

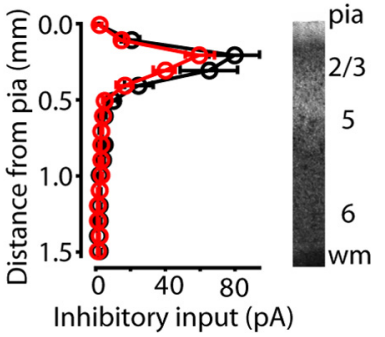

D

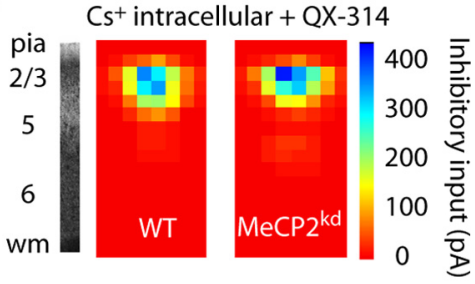

E
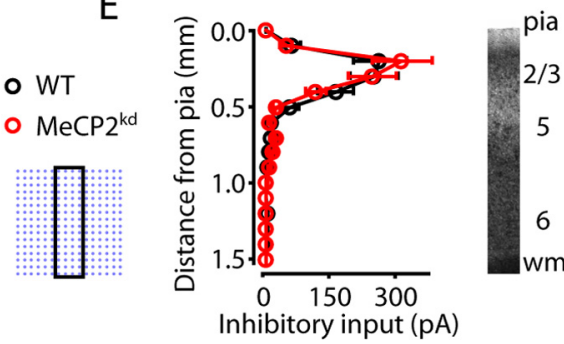

Figure 7. Local sources of inhibitory synaptic input. $A$, Trace of outward, GABAA-mediated current (black) that is completely blocked by application of $10 \mu \mathrm{m}$ SR95531 (gabazine; blue). $\boldsymbol{B}$, Maps of average GABAergic inputs from $n=13$ neighboring pairs of WT and $\mathrm{MeCP} 2^{\mathrm{kd}} \mathrm{L} 2 / 3$ pyramidal neurons recorded with $\mathrm{K}^{+}$-based intracellular solution. Maps have been zoomed slightly for display, showing topographic features in the central region of interest. C, Vertical profile of inhibitory synaptic inputs to L2/3, from neurons in $\boldsymbol{B}$. Right, Stimulation grid with columnar region of interest applies to both $\boldsymbol{C}$ and $\boldsymbol{E}$. D, Maps of average GABAergic inputs from $n=10$ neighboring pairs of WT and MeCP2 ${ }^{\mathrm{kd}} \mathrm{L} 2 / 3$ pyramidal neurons recorded with $\mathrm{Cs}^{+}$-based intracellular solution containing $1 \mathrm{~mm}$ QX-314. $\boldsymbol{E}$, Vertical profile of inhibitory synaptic inputs to $L 2 / 3$, from neurons in $\boldsymbol{D}$.

Speech and motor disturbances in Rett syndrome. Neurosci Behav Physiol 32:323-327.

Belichenko NP, Belichenko PV, Mobley WC (2009) Evidence for both neuronal cell autonomous and nonautonomous effects of methyl-CpGbinding protein 2 in the cerebral cortex of female mice with Mecp2 mutation. Neurobiol Dis 34:71-77.

Blue ME, Naidu S, Johnston MV (1999) Altered development of glutamate and GABA receptors in the basal ganglia of girls with Rett syndrome. Exp Neurol 156:345-352.

Borrell V, Yoshimura Y, Callaway EM (2005) Targeted gene delivery to telencephalic inhibitory neurons by directional in utero electroporation. J Neurosci Methods 143:151-158.

Briggs F, Callaway EM (2005) Laminar patterns of local excitatory input to layer 5 neurons in macaque primary visual cortex. Cereb Cortex 15:479-488.

Brill J, Huguenard JR (2008) Sequential changes in AMPA receptor targeting in the developing neocortical excitatory circuit. J Neurosci 28:13918-13928.

Callaway EM, Katz LC (1993) Photostimulation using caged glutamate reveals functional circuitry in living brain slices. Proc Natl Acad Sci U S A 90:7661-7665.

Canepari M, Nelson L, Papageorgiou G, Corrie JE, Ogden D (2001) Photochemical and pharmacological evaluation of 7-nitroindolinyl-and 4-methoxy-7-nitroindolinyl-amino acids as novel, fast caged neurotransmitters. J Neurosci Methods 112:29-42.

Chahrour M, Zoghbi HY (2007) The story of Rett syndrome: from clinic to neurobiology. Neuron 56:422-437.

Chahrour M, Jung SY, Shaw C, Zhou X, Wong ST, Qin J, Zoghbi HY (2008) $\mathrm{MeCP} 2$, a key contributor to neurological disease, activates and represses transcription. Science 320:1224-1229.

Chao HT, Zoghbi HY, Rosenmund C (2007) MeCP2 controls excitatory synaptic strength by regulating glutamatergic synapse number. Neuron 56:58-65

Chen RZ, Akbarian S, Tudor M, Jaenisch R (2001) Deficiency of methylCpG binding protein-2 in CNS neurons results in a Rett-like phenotype in mice. Nat Genet 27:327-331.
Chen WG, Chang Q, Lin Y, Meissner A, West AE, Griffith EC, Jaenisch R, Greenberg ME (2003) Derepression of BDNF transcription involves calcium-dependent phosphorylation of MeCP2. Science 302:885-889.

Chklovskii DB, Mel BW, Svoboda K (2004) Cortical rewiring and information storage. Nature 431:782-788.

Cohen S, Greenberg ME (2008) Communication between the synapse and the nucleus in neuronal development, plasticity, and disease. Annu Rev Cell Dev Biol 24:183-209.

Cohen S, Zhou Z, Greenberg ME (2008) Medicine. Activating a repressor. Science 320:11721173.

Collins AL, Levenson JM, Vilaythong AP, Richman R, Armstrong DL, Noebels JL, David Sweatt J, Zoghbi HY (2004) Mild overexpression of MeCP2 causes a progressive neurological disorder in mice. Hum Mol Genet 13:2679-2689.

Dani VS, Chang Q, Maffei A, Turrigiano GG, Jaenisch R, Nelson SB (2005) Reduced cortical activity due to a shift in the balance between excitation and inhibition in a mouse model of Rett Syndrome. Proc Natl Acad Sci U S A 102:12560-12565.

Eyre JA, Kerr AM, Miller S, O’Sullivan MC, Ramesh V (1990) Neurophysiological observations on corticospinal projections to the upper limb in subjects with Rett syndrome. J Neurol Neurosurg Psychiatry 53:874-879.

Fukuda T, Itoh M, Ichikawa T, Washiyama K, Goto Y (2005) Delayed maturation of neuronal architecture and synaptogenesis in cerebral cortex of Mecp2-deficient mice. J Neuropathol Exp Neurol 64:537-544.

Gemelli T, Berton O, Nelson ED, Perrotti LI, Jaenisch R, Monteggia LM (2006) Postnatal loss of methyl-CpG binding protein 2 in the forebrain is sufficient to mediate behavioral aspects of Rett syndrome in mice. Biol Psychiatry 59:468-476.

Gray NW, Weimer RM, Bureau I, Svoboda K (2006) Rapid redistribution of synaptic PSD-95 in the neocortex in vivo. PLoS Biol 4:e370.

Guy J, Hendrich B, Holmes M, Martin JE, Bird A (2001) A mouse Mecp2null mutation causes neurological symptoms that mimic Rett syndrome. Nat Genet 27:322-326.

Guy J, Gan J, Selfridge J, Cobb S, Bird A (2007) Reversal of neurological defects in a mouse model of Rett syndrome. Science 315:1143-1147.

Hagberg B, Aicardi J, Dias K, Ramos O (1983) A progressive syndrome of autism, dementia, ataxia, and loss of purposeful hand use in girls: Rett's syndrome: report of 35 cases. Ann Neurol 14:471-479.

Jones EG (1984) Laminar distribution of cortical efferent cells. New York: Plenum.

Katz LC, Dalva MB (1994) Scanning laser photostimulation: a new approach for analyzing brain circuits. J Neurosci Methods 54:205-218.

Kishi N, Macklis JD (2004) MECP2 is progressively expressed in postmigratory neurons and is involved in neuronal maturation rather than cell fate decisions. Mol Cell Neurosci 27:306-321.

Lewis JD, Meehan RR, Henzel WJ, Maurer-Fogy I, Jeppesen P, Klein F, Bird A (1992) Purification, sequence, and cellular localization of a novel chromosomal protein that binds to methylated DNA. Cell 69:905-914.

Martinowich K, Hattori D, Wu H, Fouse S, He F, Hu Y, Fan G, Sun YE (2003) DNA methylation-related chromatin remodeling in activity-dependent BDNF gene regulation. Science 302:890-893.

Moretti P, Zoghbi HY (2006) MeCP2 dysfunction in Rett syndrome and related disorders. Curr Opin Genet Dev 16:276-281.

Nelson ED, Kavalali ET, Monteggia LM (2006) MeCP2-dependent transcriptional repression regulates excitatory neurotransmission. Curr Biol 16:710-716.

Noctor SC, Flint AC, Weissman TA, Dammerman RS, Kriegstein AR (2001) Neurons derived from radial glial cells establish radial units in neocortex. Nature 409:714-720. 
Noctor SC, Flint AC, Weissman TA, Wong WS, Clinton BK, Kriegstein AR (2002) Dividing precursor cells of the embryonic cortical ventricular zone have morphological and molecular characteristics of radial glia. J Neurosci 22:3161-3173.

Percy AK (2002) Rett syndrome. Current status and new vistas. Neurol Clin 20:1125-1141.

Pettit DL, Helms MC, Lee P, Augustine GJ, Hall WC (1999) Local excitatory circuits in the intermediate gray layer of the superior colliculus. J Neurophysiol 81:1424-1427.

Ramocki MB, Zoghbi HY (2008) Failure of neuronal homeostasis results in common neuropsychiatric phenotypes. Nature 455:912-918.

Saito T, Nakatsuji N (2001) Efficient gene transfer into the embryonic mouse brain using in vivo electroporation. Dev Biol 240:237-246.

Schubert D, Staiger JF, Cho N, Kötter R, Zilles K, Luhmann HJ (2001) Layer-specific intracolumnar and transcolumnar functional connectivity of layer V pyramidal cells in rat barrel cortex. J Neurosci 21:3580-3592.

Shahbazian M, Young J, Yuva-Paylor L, Spencer C, Antalffy B, Noebels J, Armstrong D, Paylor R, Zoghbi H (2002) Mice with truncated MeCP2 recapitulate many Rett syndrome features and display hyperacetylation of histone H3. Neuron 35:243-254.

Shepherd GMG (2006) Imaging cortical circuits with laser scanning photostimulation. In: Visualizing large-scale patterns of activity in the brain: optical and electrical signals (Buzsáki G, ed), pp 54-59. Washington, DC: Society for Neuroscience.

Shepherd GMG, Svoboda K (2005) Laminar and columnar organization of ascending excitatory projections to layer $2 / 3$ pyramidal neurons in rat barrel cortex. J Neurosci 25:5670.

Shepherd GMG, Pologruto TA, Svoboda K (2003) Circuit analysis of experience-dependent plasticity in the developing rat barrel cortex. Neuron 38:277-289.

Shepherd GMG, Stepanyants A, Bureau I, Chklovskii DB, Svoboda K (2005)
Geometric and functional organization of cortical circuits. Nat Neurosci 8:782-790.

Sledz CA, Williams BR (2004) RNA interference and double-strandedRNA-activated pathways. Biochem Soc Trans 32:952-956.

Tabata H, Nakajima K (2001) Efficient in utero gene transfer system to the developing mouse brain using electroporation: visualization of neuronal migration in the developing cortex. Neuroscience 103:865-872.

Trachtenberg JT, Chen BE, Knott GW, Feng G, Sanes JR, Welker E, Svoboda $\mathrm{K}$ (2002) Long-term in vivo imaging of experience-dependent synaptic plasticity in adult cortex. Nature 420:788-794.

Tropea D, Giacometti E, Wilson NR, Beard C, McCurry C, Fu DD, Flannery R, Jaenisch R, Sur M (2009) Partial reversal of Rett Syndrome-like symptoms in MeCP2 mutant mice. Proc Natl Acad Sci U S A 106:20292034.

Wang H, Chan SA, Ogier M, Hellard D, Wang Q, Smith C, Katz DM (2006) Dysregulation of brain-derived neurotrophic factor expression and neurosecretory function in Mecp2 null mice. J Neurosci 26:10911-10915.

Weiler N, Wood L, Yu J, Solla SA, Shepherd GMG (2008) Top-down laminar organization of the excitatory network in motor cortex. Nat Neurosci 11:360-366.

Yu J, Anderson CT, Kiritani T, Sheets PL, Wokosin DL, Wood L, Shepherd GMG (2008) Local-circuit phenotypes of layer 5 neurons in motorfrontal cortex of YFP-H mice. Front Neural Circuits 2:6.

Zhou Z, Hong EJ, Cohen S, Zhao WN, Ho HY, Schmidt L, Chen WG, Lin Y, Savner E, Griffith EC, Hu L, Steen JA, Weitz CJ, Greenberg ME (2006) Brain-specific phosphorylation of $\mathrm{MeCP} 2$ regulates activity-dependent Bdnf transcription, dendritic growth, and spine maturation. Neuron 52:255-269.

Zoghbi HY (2003) Postnatal neurodevelopmental disorders: meeting at the synapse? Science 302:826-830. 